\title{
Sensor-based mobile robot for harsh environments: functionalities, energy consumption analysis and characterisation
}

\author{
Roberto De Fazio ${ }^{1}$, Dany Mpoi Katamba², Aimè Lay Ekuakille, Miguel Joseph Ferreira², Simon \\ Kidiamboko ${ }^{2}$, Nicola Ivan Giannoccaro ${ }^{1}$, Ramiro Velazquez ${ }^{3}$, Paolo Visconti ${ }^{1}$ \\ ${ }^{1}$ Department of Innovation Engineering, University of Salento, Lecce 73100, Italy \\ 2 Department of Electronics, Institut Supérieur de Techniques Appliquées - ISTA University, Kinshasa, DR Congo \\ ${ }^{3}$ Faculty of Engineering, Universidad Panamericana, Aguascalientes 20290, Mexico
}

\begin{abstract}
Mobile robots and rovers play an important role in many industrial applications. Under certain constraints, they are suitable in harsh environments and conditions in which protracted human activity is not safe or permitted. In many circumstances, mechanical aspects and electrical consumption need to be optimized for autonomous and wheeled mobile robots. The paper illustrates the design of a semicustom wheeled mobile robot with high-efficiency mono- or polycrystalline photovoltaic panel on the roof that supports the lithium ion batteries during particular tasks (e.g. navigating rough terrain, obstacles or steep paths) to extend the robot's autonomy. An electronic controller was designed, and data acquisition related to power consumption performed using a specific experimental setup. The robot can detect parameters such as temperature, humidity, concentrations of toxic gas species and the presence of flames, making it particularly suitable for contaminated environments or industrial plants. For this aim, the mobile robot was equipped with a wide range of commercial sensors and a Global Positioning System receiver to track its position. In addition, using an HC-06 Bluetooth transceiver, the robot receives commands and instructions, and sends the acquired data to the developed loTool smartphone application, where they are displayed to be analysed by user.
\end{abstract}

Section: RESEARCH PAPER

Keywords: mobile robots; photovoltaic system; electronic control; energy consumption measurements; sensors; instrumentation; autonomous vehicles

Citation: Roberto De Fazio, Dany Mpoi Katamba, Aimè Lay Ekuakille, Miguel Joseph Ferreira, Simon Kidiamboko, Nicola Ivan Giannoccaro, Ramiro Velazquez, Paolo Visconti, Sensor-based mobile robot for harsh environments: functionalities, energy consumption analysis and characterisation, Acta IMEKO, vol. 10, no. 2, article 29, June 2021, identifier: IMEKO-ACTA-10 (2021)-02-29

Section Editor: Francesco Lamonaca, University of Calabria, Italy

Received August 6, 2020; In final form March 17, 2021; Published June 2021

Copyright: This is an open-access article distributed under the terms of the Creative Commons Attribution 3.0 License, which permits unrestricted use, distribution, and reproduction in any medium, provided the original author and source are credited.

Corresponding author: Paolo Visconti, e-mail: paolo.visconti@unisalento.it

\section{INTRODUCTION}

The safety of human beings working in harsh environments is a theme of major concern for workers, entrepreneurs and policymakers. 'Harsh environment' here signifies a hostile environment for human beings, whether indoors or outdoors. Interest in autonomous mobile robots is increasing day by day; a brief overview of such applications makes clear their paramount importance. In hazardous industries, like those involving chemicals, oil and steel, many risks threaten human safety and the quality of goods. In the cracking processes used in the chemical and petrochemical industries, for instance, individual and group protections are necessary to lower exposure to gaseous and odorous components containing volatile organic compounds [1], [2]. In oil production sites, such as refineries, liquid, solid and gaseous materials present high risks for persons and goods. In the latter case, flammable materials can start fires, so protection devices are needed to prevent combustion. The steel industry also faces the above risks and an increased probability of accidents due to a direct and indirect combination of diverse materials and dangerous situations. Protective masks with special filters are used to address some of these hazards [3].

In outdoor sites, robotic vehicles are of interest for safety, as illustrated above, but also for security, as, for example, in cases where there is a risk of explosions. Security forces use mobile robots to monitor and penetrate hostile areas instead of employing humans [4]. In hospital pavilions and wards, levels of exposure are controlled to protect patients and healthcare 
workers from risks, such as COVID-19 infection [5] or toxic gas/water leaks [6]. In this context, mobile robots designed for the automotive sector can be used to perform inspections and monitoring and to work as remote actuators [7]. For autonomous mobile robots, energy consumption is a truly basic issue; an analysis and design related to this aspect is also illustrated in the manuscript.

Photovoltaic (PV) systems are becoming an important support in many applications; for instance, in agriculture they are used to monitor environment and soil parameters [8], predict floods [9] and optimise irrigation cycles and crop growth [10], [11]. Moreover, PV systems are useful for robotic vehicle applications. Some examples of mobile robots powered by solar energy are present in the scientific literature: [12] presented a light $(500 \mathrm{~g}$, including the controller) robotic system made of Lego bricks and powered by 32 small $0.08 \mathrm{~W}$ solar panels that carried an additional weight of only $180 \mathrm{~g}$. In [13], a vehicle powered by solar energy that can be utilised to monitor the status of unstable transmission control protocol/internet protocol networks is presented with the aim of reducing downtime for the network itself. The robot is able to follow a path defined by a track line using infrared (IR) sensors and is powered by solar energy; its energy autonomy and utilisation in terms of network management are discussed.

In [14], the design of another solar-powered robotic vehicle is proposed, including a solar tracking system to increase the robot's energy autonomy together with two batteries, one directly recharged by the PV panel and one that provides energy to the robotic vehicle during the charging phase of the first battery or in case of the total absence of solar radiation. The switching system between the two batteries consists of two selectors driven by the microcontroller using a pulse-width modulation (PWM) signal.

The latest generations of robotic vehicles used for space exploration make use of solar power systems: energy for the rover Sojourner was generated via a small PV panel. Rechargeable batteries were used for the first time in a space mission in the Mars exploration rovers, where the need for greater operational autonomy in the Opportunity and Spirit rovers was solved by using very large solar panels. Aspects that could be improved for future generations of exploration vehicles include the efficiency of the PV materials used to produce cells and the possibility of tracking maximum light intensity. For example, [15] proposed the design of a mechanism capable of tracking maximum light intensity independently from rover mobility. The mechanism was applied to a commercial robotic platform (VANTER) provided with a PV panel and a pack of two lithium polymer (Lipo) batteries continuously recharged by the PV system.

An interesting review paper discussed the relationship between solar cells and robotics by analysing existing literature related to the solar cells applied to different robotic applications [16]. The authors showed that improvements in the two fields (i.e. solar cell production and robotics) contribute to better living and a cleaner environment through the renewable energy provided by solar cells and the automatic work provided by robotics.

A recent quantitative analysis of the power contribution of solar cells in a mobile robot is reported in [17], which analysed the behaviour of a simple two-wheel differential-driven mobile robot. The main controller of the solar-powered robot is an Arduino Mega 2560 that receives input data from two position sensors and controls the robot's movements by driving the direct current (DC) motors. A $1.5 \mathrm{~W} / 12 \mathrm{~V}$ solar panel is used to charge the supercapacitor bank that supplies power to the robot. The solar-powered robot is also equipped with a voltage sensor to monitor the amount of charge continuously injected into the capacitor bank. The robot moves from one station to three others, simulating the stations in a factory scenario. Supercapacitor charging was conducted for five days to detect any fluctuation due to external factors, such as weather conditions. The highest voltage value obtained in a day of charging was $4.96 \mathrm{~V}$, with about 100,000 lux of irradiance received by solar cells while the robot moved, discharging the batteries during its task.

Another recent contribution discussed the design and implementation of a dual-axis tracker for PV panels able to provide additional power and thereby extend the operating time of a cleaning robot [18]. The dual-axis solar tracker worked by using four light sensors to compare the light intensity in order to determine the direction of incoming light. The reported experimental results showed that the highest output voltage reached $6.10 \mathrm{~V}$ for light intensity values from 110,800 up to 116,500 lux when the PV panel was orthogonal to the position of the sun, with a tolerance of $0-10$ degrees. The average time to charge the battery from $2.5 \mathrm{~V}$ to $3.7 \mathrm{~V}$ using the PV panel was about 94 minutes. An additional PV panel permitted a longer operation time (an increase of 7 minutes and 17 seconds) for the cleaning robot.

In the present paper, a specific robotic vehicle was designed and realised, and the related energy consumption was determined and minimised through several procedures. The heart of the system is an Arduino R3 controller that drives four DC motors (model MOT-03696, manufactured by DaguRobot) and supervises a Bluetooth HC-06 module and a sensing unit. We used experimental tests to quantify the contribution of each PV panel by considering changes in different parameters, such as the kinematics of the robot, the ambient temperature, the PV material (monocrystalline silicon [mono-Si] or polycrystalline silicon [poly-Si]), etc., in order to provide important and novel information for the future development of solar-powered robotic vehicles.

The developed mobile robot was intended to detect the parameters in harsh environments where operating conditions are too dangerous for human intervention. The proposed solution makes it possible to safely inspect dangerous areas and determine if conditions are appropriate for subsequent human intervention. The robot is equipped with different sensors (e.g. to detect dangerous and harmful gases, flames and temperature) and a Global Positioning System (GPS) receiver to inspect the considered area and track the vehicle's position. In this context, several applicative scenarios can be identified, such as the inspection of empty tanks that previously contained chemicals, fuels or cereals or environments in which fires or gas leaks have occurred. The mobile robot includes an HC-06 Bluetooth transceiver to transmit the acquired data to the developed IoTool application, where the data are displayed and analysed, and receive instructions related to the operation of the mobile robot. Thanks to the IoTool application, a smartphone can act as an IoT gateway, enabling the mobile robot to operate in remote mode as well as in outdoor areas where internet access points are not available.

The paper is organised as follows: Section 2 describes the design of the mechanical and electrical units of the mobile robot and introduces the fundamental equations used to estimate the energy requirements; Section 3 reports the results related to the 
robot's power consumption, taking into account the contribution of the auxiliary solar energy harvesting system, which employed two different PV panel technologies. An analysis of the performances of the two commercial PV panels as a function of incident irradiance and temperature is reported. Moreover, the sensors and devices equipping the robot and the developed IoTool applications are introduced and fully described. Finally, the conclusions are summarised in Section 4.

\section{MOBILE ROBOT DESIGN AND ENERGY ANALYSIS}

\subsection{Mechanical realisation and energy consumption evaluation}

The autonomous wheeled mobile robot was assembled partly with commercial components and partly with other devices adapted for the research; hence, it is a semi-custom vehicle.

The energy consumption model for the mobile robot is divided into three components that are related to the following parts: the sensing system, the control system and the motion system. The energy consumption $E_{s}$ of the sensing system is obtained by multiplying the electrical power consumption $P_{s}$ by the time interval $\Delta t$, as reported in equation (1)

$$
E_{S}=P_{S} \cdot \Delta t \text {. }
$$

The energy consumption of the sensing system depends on the robot's speed. Fast sensor data transmission allows the robot to quickly monitor the surrounding environment. The speed of the mobile robot can range from low to high; if it is moving slowly and not working constantly, the sensors can wait for the robot to move and then detect the parameters of interest again. Similarly, when the robot is in a standby state, there is no need to monitor its surroundings, so the sensors are set to sleep mode. When the robot reaches its maximum speed, the surrounding environment changes very quickly; thus, the sensors need to work continuously. Equation (2) illustrates the overall energy consumption of the robot's sensing system, which is proportional to the speed:

$$
E_{S}=\frac{1}{V_{\max }} \cdot \int\left(v \cdot P_{S}\right) d t
$$

where $V_{\max }$ is the maximum speed of the mobile robot. Obviously, this method allows us to drastically reduce the energy consumption of the sensing system in comparison to a scenario in which the sensors work continuously.

The energy consumption of a robot may be predicted by a statistical model that only depends on the robot's path [19]; the authors in [19] proposed a probabilistic, data-driven approach to estimating a mobile robot's energy consumption on a set of trajectories. In this approach, the robot was treated as a black box, thereby removing the reliance on often unavailable system characteristics. They measured the consumption on the traversed routes directly and utilised features derived from publicly available maps to extrapolate energy consumption for real-world routes and then predict consumption for untravelled roads. The variance in the proposed statistical model is due to exogenous latent factors, such as traffic and weather conditions. In detail, the energy model derived from [19] and proposed in [20] is divided into the following three parts: energy consumption in the standby state, energy consumption when the wheeled robot first starts to move and, finally, energy consumption when the robot is running smoothly. The model can be stated as follows:

$$
E_{\text {control }}=\left\{\begin{array}{c}
E_{\text {standby }}=P_{\text {standby }} \cdot \Delta t \\
E_{\text {startup }}=\int\left(\Phi \cdot \Delta \mathrm{v}+\left(\frac{t^{2}}{10}\right)+P_{\text {standby }}\right) \\
E_{\text {stable }}=\int\left(P_{\text {standby }}+t^{2}\right) d t
\end{array}\right.
$$

where $P_{\text {standby }}$ represents the power of the control sections (with the robot stopped), $\Phi$ is the starting factor that determines the energy demand for the controller during the robot's startup phases, $\Delta v$ is the rate of change at the current moment and $t$ is the time when the robot starts moving. It is determined that the control system only accepts the sensors' signals during the standby phase, so the power is constant. The $t^{2}$ terms model the power consumption of the robot's control system (dissipated as thermal power) as a function of the execution time, both in the startup $\left(E_{\text {startup }}\right)$ and steady $\left(E_{\text {stable }}\right)$ conditions. From a dimensional point of view, this term is implicitly weighted by the power consumption/time parameter expressed in $\mathrm{W} / \mathrm{s}^{2}$, which relates to the control board. Concerning the motion system, energy consumption can be divided into four parts: traction energy consumption, the increase of kinetic energy, friction energy dissipation and energy dissipated in thermal form (see (4)). As reported above, the robot's motion can be divided into standby, startup and stable operation modes; in the startup mode, an instantaneous pulse sends the start signal to the electric motors. When the robot moves, it enters the stable operation mode:

$$
E_{\text {motion }}=\int P_{\text {motion }} d t=E_{k}+E_{f}+E_{e}+E_{m}
$$

where $E_{\text {motion }}$ is the energy consumed to attain and sustain the robot's motion, $E_{\mathrm{k}}$ is the kinetic energy (depending on the robot's mass $M$ and velocity $v$ ), $E_{\mathrm{f}}$ is the energy dissipated due to friction during the movement of the robot (depending on the friction coefficient between the wheels and the ground), $E_{\mathrm{e}}$ is the energy dissipated as heat in the armatures of the motors and $E_{\mathrm{m}}$ is the mechanical dissipation caused by overcoming the friction torque in the actuator. A simulation presented in [20] demonstrated that, in the classical condition of the robot's movement, the most important energy contributions are given by $E_{\mathrm{k}}$ and $E_{\mathrm{m}}$. Thus, once the geometry and kinematics of the mobile robot are fixed, it is possible to preliminarily evaluate the energy and power requested for the motion.

The main aim of the research is to study a method to optimise wheeled autonomous and mobile robots in terms of energy consumption. In this context, it was decided to design a semicustom vehicle starting from a partly commercial robot and completing its construction by adding the control electronics, a sensing system with low-power sensors and an auxiliary battery recharged by the PV panel. Reverse engineering (RE) was adopted in the robot's design [21], [22]; RE is a common scientific/technical activity used to reprocess existing items or products.

Unlike forward engineering, RE is based on the modification of a fully or partially existing system; the reverse engineer must not only provide a plan for the actual realisation of the system but also a plan for the transformations and justifications for their application. Given this concept, we studied the available mobile robot and related items, and we used a dedicated software, SolidWorks (developed by Dassault Systèmes) [23], to redesign the whole vehicle and the additional parts that were used to complete the system. These additional sections are the following: 
the hosting structure for the PV panel, the case for the ATmega328 microcontroller [24], the sensor chassis and an additional electronic control board. Figure 1 illustrates the different conceptual steps of the RE vehicle design, in which the outcomes were updated to serve the purposes of the research, and Figure 2 shows a photo of the assembled sensor-based vehicle moving on the laboratory floor.

The model created using SolidWorks considered the components' mass characteristics and allowed a preliminary check on any structural problems in the mobile base or accumulations of mechanical stress in particular points of the structure. The subsequent implementation of the mobile robot made it possible to test the device's dynamic behaviour directly in the field. From the perspective of mechanical construction, all spare parts were assembled to reduce vibrations to a minimum. Further mechanical vibrations are a source of energy loss.

\subsection{Functional and electronic schemes and experimental setup}

In order to quantify the power consumption, it is necessary to understand the real power demands of the different units involved in operating the robotic vehicle. Figure 3 shows the main components and units of the designed sensor-based vehicle controlled by the Arduino Uno board based on an ATmega 328 microcontroller. In detail, the four DC motors allow movement of the wheels through the L298N full-bridge motor-driving module (manufactured by STMicroelectronics). The heart of the

a)

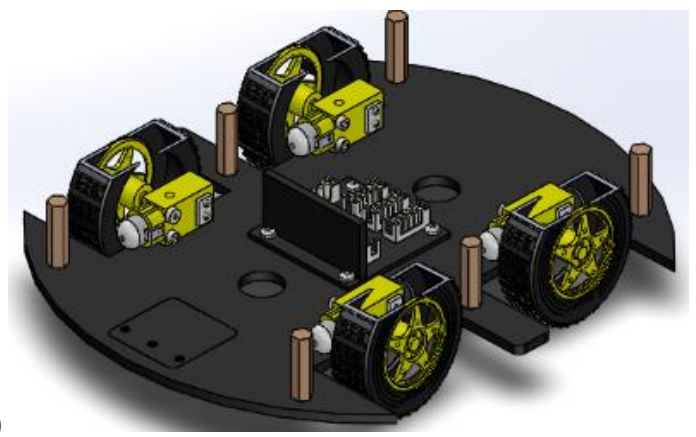

b)
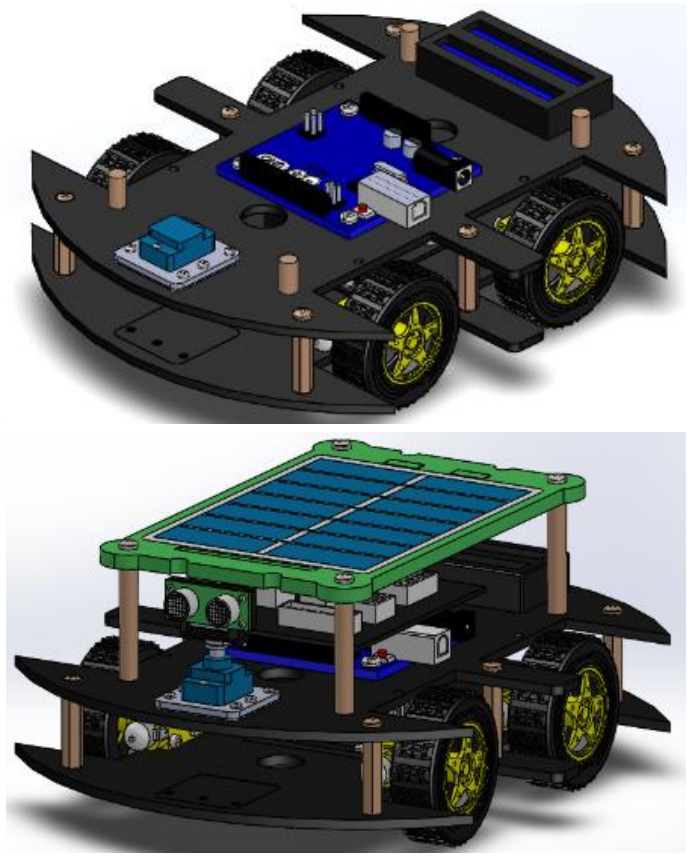

Figure 1. Conceptual RE design using SolidWorks: a) basic vehicle chassis, b over-lapping plate hosting the electronics and rechargeable batteries and c) full 3D vehicle including IR and ultrasonic (US) sensors.

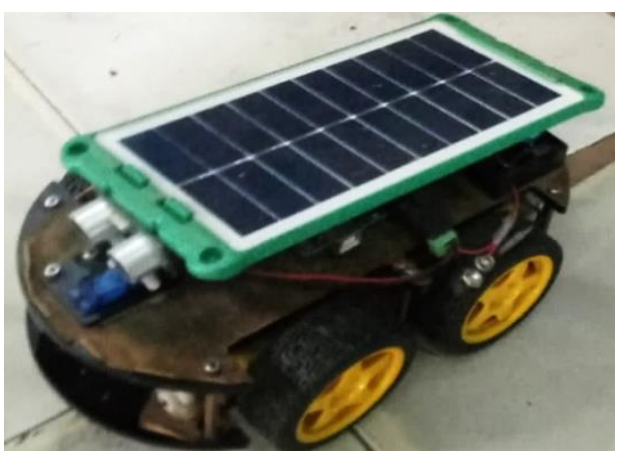

Figure 2. Assembled vehicle with the solar panel installed on the roof.

system is the Arduino R3 acquisition and processing board, which also controls the HC-06 Bluetooth module and the power supply sections of the system.

Bluetooth technology was chosen for this application for two reasons: the ease of interfacing with smart devices (e.g. PCs, tablets or smartwatches), which are all equipped with Bluetooth transceivers to exchange data and commands, and the suitability of the coverage range $(<100 \mathrm{~m})$ for the potential applications of the proposed system, such as inspecting tanks or pipelines and verifying the safety of environments in the presence of dangerous gas leaks. Standard Bluetooth was preferred over Bluetooth Low Energy due to its compatibility with the software development tools.

The mobile robot consumes $9.3 \mathrm{~W}$ of power (at maximum speed but without obstacles or energy loss), which are provided by an on-board battery pack consisting of two 9,900 mAh lithium ion (Li-Ion) batteries (the blue cylindrical packages in Figure 6) connected in parallel. These batteries (manufactured by GTF, model TR18650, 3.7 V nominal voltage) ensure an autonomy of more than five hours in the worst-case condition, corresponding to continuous current absorption of 2.5-2.6 A [25]. However, if additional power is required, in case of friction and/or complicated paths, a parallel solar energy harvesting system was installed to automatically boost the robot when needed, as described below. Advances in the manufacturing of low-cost, high-performance solar panels and the availability of efficient and integrated electronic conditioning systems have enabled the simple integration of solar harvesting technology in IoT or robotic applications [26]-[28]. Given the small size of the vehicle's roof, a $1.8 \mathrm{~W} / 5 \mathrm{~V}$ monocrystalline solar panel (manufactured by Shenzen Portable Electronic Technology C.

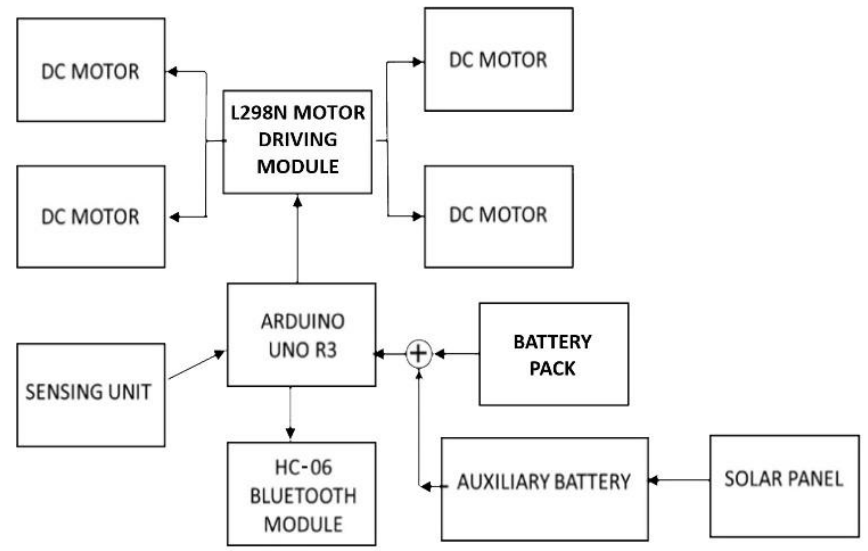

Figure 3. Functional flowchart of the different sections of the designed mobile robot, all supervised by Arduino and connected to the power supply unit. 
Ltd, model PETC-SE1.8) and a $2 \mathrm{~W} / 6 \mathrm{~V}$ polycrystalline solar panel (manufactured by Solidal, model 130 110-3) were selected for the experiment. In particular, the energy harvesting system includes a CN3791-based solar charger (manufactured by Consonance Electronics) and a PWM switch-mode battery charger controller designed for solar harvesting applications; it can charge the battery in constant-current or constant-voltage mode, ensuring a regulated voltage equal to $4.2 \mathrm{~V} \pm 1 \%$ (Figure 4). Furthermore, the $\mathrm{CN} 3791$ solar charger features a wide input voltage range $(4.5 \div 28 \mathrm{~V})$, a maximum output current of $4 \mathrm{~A}$ and a maximum power point tracking function to optimise the power extraction from the solar panel.

The CN3791-based board is equipped with two distinct outputs that are connected in parallel, allowing the battery to be connected to the first output and the electric load to the second. The charge scavenged by the solar panel is stored in a 4,000 $\mathrm{mAh}$ single-cell Lipo battery (model 905165, manufactured by EHAO Tech. Co., Ltd), connected in parallel to the mobile robot's battery pack. The path from the auxiliary battery is dynamically enabled using a Mosfet switch (model IR630, manufactured by STMicroelectronics), based on the overall current absorbed by the mobile robot, which is detected by an ACS712 current sensor (manufacture by Allegro MicroSystems) installed along the main power supply line (Figure 4). the Arduino Uno main board acquires the signal from the sensor, and if the overall current absorbed is higher than $2.5 \mathrm{~A}$, for instance when the mobile robot moves over rough ground, the auxiliary power supply path from the energy harvesting system is enabled.

The Arduino Uno is a rapid prototyping board based on the ATmega 328P microcontroller; it has a wide range of peripherals, including 20 digital input/output pins, of which six can be set as PWM outputs and six as analogue channels, and an integrated 10-bit analogue-to-digital converter. Furthermore, the microcontroller integrates a single universal asynchronous receiver-transmitter (UART) interface and two-wire interface and serial peripheral interface (SPI) modules, enabling easy interfacing with sensors and other external devices.

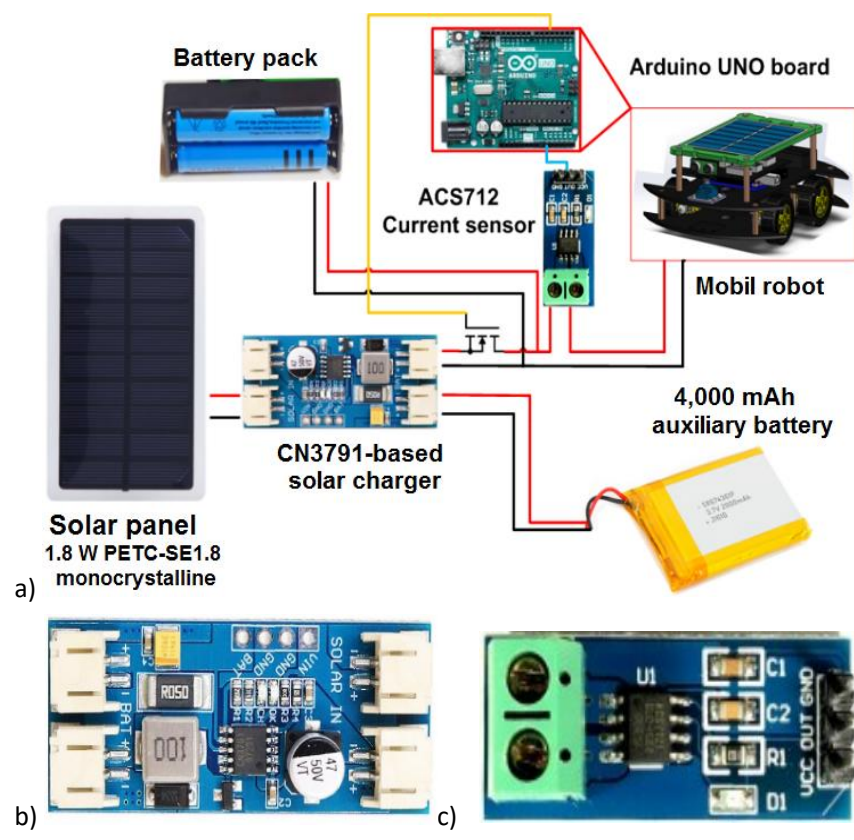

Figure 4. a) Schematic representation of the auxiliary solar harvesting system used to boost the mobile robot when more power is required; b) the CN3791based board and c) the ACS712 current sensor.

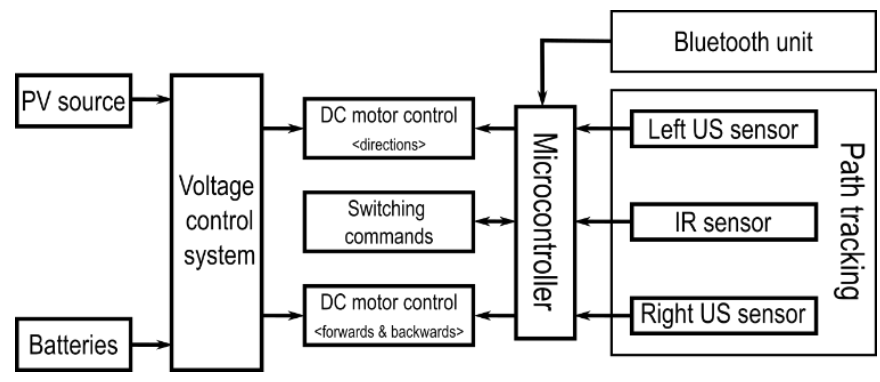

Figure 5. Detailed functional block diagram of the power, control and driving systems of the mobile robot, with the microcontroller as the core component.

Figure 5 shows a block diagram of the designed system with the ATmega 328 microcontroller that supervises all the vehicle systems. The PV-charged auxiliary and primary batteries are connected in parallel, when needed, to feed the whole system. When the required power becomes greater than $9.25 \mathrm{~W}$, which corresponds to a current of $2.5 \mathrm{~A}$ ( $3.7 \mathrm{~V}$ provided by batteries), the auxiliary battery is connected to increase the available current and extend the lifetime of the primary batteries. The sensing system includes sensors for different applications; for path tracking, US and IR sensors are employed to control the robot's motion [29]-[31]. Thus, sensor-based path tracking allows the mobile robot to be guided during its movement from one point to another.

Comparing different PV panels (i.e. mono-Si and poly-Si) is important because changes in solar irradiance affect the energy harvesting system's ability to provide power. A power contribution of $20 \%$ from the PV system is crucial for the robot's operation, but this contribution depends on the solar irradiance value and the panel's temperature.

The experimental setup, shown in Figure 6, included the following main components: 1) the wheeled robot under measurement to determine its power consumption, 2) a Hall effect sensor, 3) National Instruments' NI myDAQ, 4) a PC displaying the acquired current signal and 5) a $220 \mathrm{~V}-15 \mathrm{~V}$ converter (5). A current Hall effect sensor was used to measure the current absorbed by the tracking and environmental sensors and by the four DC motors; in addition, the overall power consumption of the mobile robot was monitored by measuring the current values absorbed directly from the battery pack.

For this purpose, a custom smartphone application was developed using MIT App Inventor to control the robot's movements, manage the sensing system as a function of the specific application and reduce the robot's power consumption.

The experimental tests were carried out at ISTA University's mechatronics laboratory (Kinshasa, DR Congo). The wheeled robot, controlled by a mobile application, moved over the laboratory's ceramic floor, travelling forward for $6 \mathrm{~m}$ at a constant speed of $1.5 \mathrm{~m} / \mathrm{s}$. Therefore, the robot took a bit more than $4 \mathrm{~s}$ (including the time required to achieve the final velocity) to travel the fixed distance. Energy consumption was measured during this time. To verify the impact of the PV panels, the vehicle was used outside under different solar radiation conditions. The obtained experimental results are reported in the next section.

\section{SYSTEM TESTING AND EXPERIMENTAL RESULTS}

The objective of this section is to illustrate the results of the experiments carried out in the laboratory and outdoors. The latter condition was important in order to test the behavioural 


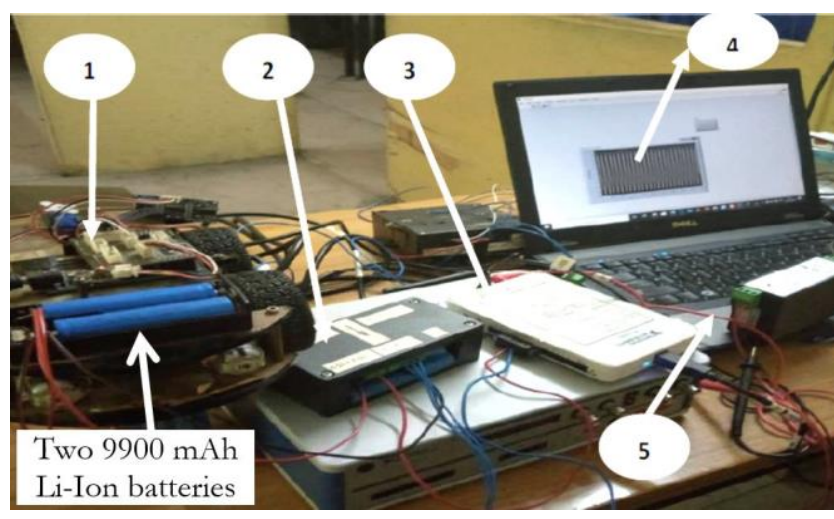

Figure 6. Experimental setup for the energy consumption analysis, with a dedicated acquisition architecture and measurement system.

capabilities of the wheeled vehicle when working outdoors and in stress conditions (namely, during operating modes with high current absorption by the motors, such as when the wheels are blocked due to an obstacle on the path or the terrain is rough). The outdoor experiments were also done to highlight the differences between the two types of PV panels able to supply $20 \%$ of the total energy amount required by the mobile robot during diurnal activities (but obviously not during night operations).

The experiments aimed to verify the dependencies between the trend of the absorbed current and the operating conditions under stress suffered by the robot due to any obstacles along the path or sudden changes in trajectory that cause speed variations. It should be noted that the average speed of the wheeled robot was about $1.5 \mathrm{~m} / \mathrm{s}$. It was set up to advance and reverse after a certain time, and our tests were carried out on a surface that allowed the wheels to turn freely. Although the mobile robot travelled at a constant speed, Figure 7 a shows a variation in current over time because the robot moved back and forth; during the change of direction, an abrupt braking occurred, which affected current consumption.

Specifically, Figure $7 \mathrm{a}$ depicts the trend of mean current absorbed by the entire mobile robot (the blue dashed curve), including the contributions of the motors and the acquisition and driving sections, and the mean current absorbed by the mobile robot's four motors alone (the black curve). The electronic acquisition and driving units draw a mean current of about $100 \mathrm{~mA}$, as detailed below. Another ACS712 current sensor was placed under the motor driver and connected to the acquisition board to measure the overall current absorbed by the motors. Subsequently, as a stress test for both mechanical capability and energy consumption, the wheels were blocked and then released after a short time, which caused the current absorbed by the motors to rapidly increase until reaching a maximum value of 2.8-2.9 A (Figure 7b). This figure also illustrates the trend of current absorption by the whole robot (the blue dashed curve). The maximum current is guaranteed by the supporting action of the auxiliary battery powered by the PV panel, which acts when the measured current exceeds $2.5 \mathrm{~A}$. The red dashed line in Figure $7 \mathrm{~b}$ indicates the threshold current value (i.e. $2.5 \mathrm{~A}$ ), which triggers the intervention of the auxiliary battery charged by the solar harvesting section. This intervention was activated after about 3.6 seconds and continued until the end of the test (10 seconds) (Figure $7 b$ ).

Furthermore, several indoor tests were performed using different constant speeds (from $0.5 \mathrm{~ms}^{-1}$ up to $1.5 \mathrm{~ms}^{-1}$ ) and straight paths. When the robot's speed was reduced, a

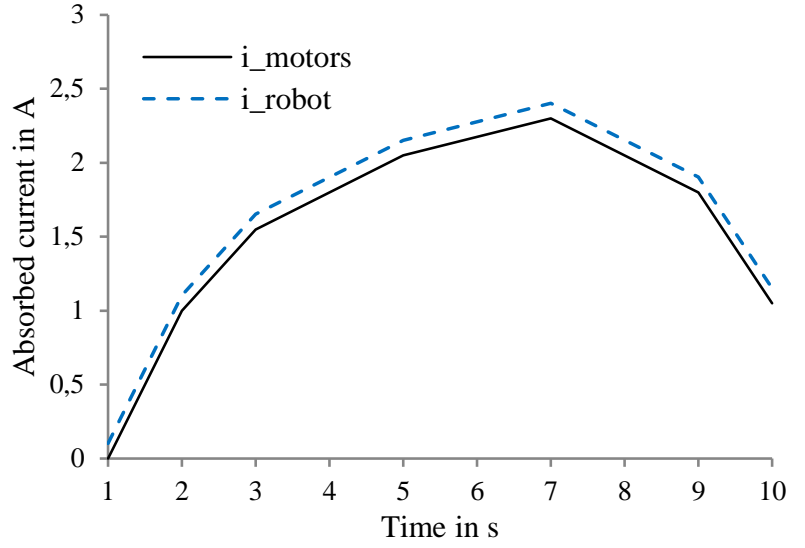

a)

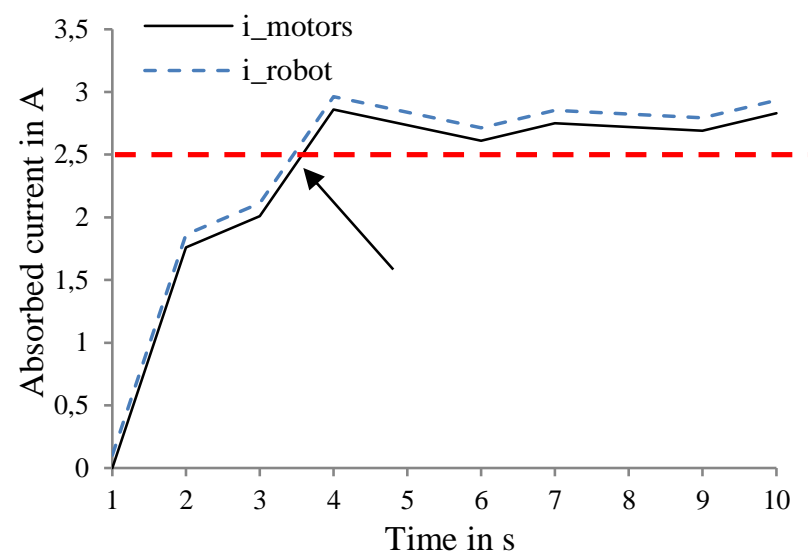

Figure 7. Current absorbed by batteries as a function of time during indoor tests: a) normal conditions; b) stress condition due to blocked wheels. The dotted red line indicates the threshold current value that activates the PV system's supporting action.

proportionally lower current value was absorbed from the battery; for instance, at a speed of $0.5 \mathrm{~ms}^{-1}$, the robot's motors drew an overall current of $0.63 \mathrm{~A}$, while a constant velocity of $1.5 \mathrm{~ms}^{-1}$ correlated to a current absorption of $1.52 \mathrm{~A}$ on a smooth path. The developed robot implements two firmware strategies for tuning the speed as a function of the battery level in order to extend the battery's lifetime. We developed a dual regulation mechanism; a remote control system allows the smartphone application to halve the set speed regardless of the battery status. We also implemented an automatic control mechanism that halves the robot's speed when the battery voltage falls below 3.75 $\mathrm{V}$, corresponding to $40 \%$ of residual battery capacity.

After the indoor tests, several outdoor experiments were performed in order to verify the contribution of each PV panel according to their technology (mono-Si and poly-Si) [32]. The PV panels, detailed in section 2.2, were tested to determine their contributions as a function of the solar irradiance and the panel's temperature during the wheeled robot's movements. All outdoor experiments were carried out in Kinshasa (DR Congo) during January, February and March 2020, as these are the warmest months in that area. Figure 8 shows the average hourly temperature (the purple line) over three months (January, February and March 2020, respectively), with purple areas indicating the $25^{\text {th }}$ to $75^{\text {th }}$ and $10^{\text {th }}$ to $90^{\text {th }}$ percentile bands [33]. The thin dotted line is the average hourly perceived temperature. Civil twilight and night are indicated by the shaded overlays. Figure 8 demonstrates the repeatability of the trend of the average temperature during the day, with values varying from $23.3^{\circ} \mathrm{C}$ to $30^{\circ} \mathrm{C}$ in January, from $23.3^{\circ} \mathrm{C}$ to $30.5^{\circ} \mathrm{C}$ in February 
and from $23.3^{\circ} \mathrm{C}$ to $31.1^{\circ} \mathrm{C}$ in March, representing a very small variation of the maximum temperature value in the considered months.

The experimental validation was carried out by measuring the generated power during the robot's outdoor navigation (using the same conditions as in the indoor tests) during the day as a function of the incident solar irradiance, which was detected by a digital pyranometer (model HT204, manufactured by HT Instruments). The aforementioned quantities were acquired every 15 minutes, starting at $10 \mathrm{am}$, for a total temporal range of 5 hours. The characterisation results are shown in Figure 9 and 10 for the mono-Si and poly-Si panels, respectively. In addition, the temperature of the panels was measured with an IR thermometer (model DEM100, manufactured by Velleman), and a first approximation was modelled, showing an increasing linear trend with the incident irradiance (Figure 9 and Figure 10). The measured power trends (the blue lines) have been compared with the ideal ones (the dotted red lines), which were obtained by assuming a constant conversion efficiency (i.e. $19 \%$ for the monocrystalline panel [34] and $16 \%$ for the polycrystalline one [35]) for high irradiance ( $>300 \mathrm{~W} / \mathrm{m}^{2} / 37,974$ lux) and taking into account the parasitic effects emerging for low irradiance levels (e.g. shunt resistance).

As can be seen for both solar panels, when the solar irradiance (and therefore the panel temperature) increases, the measured

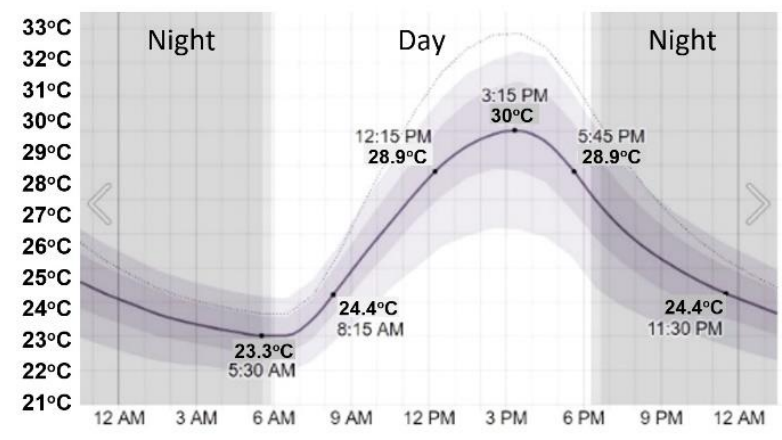

a)

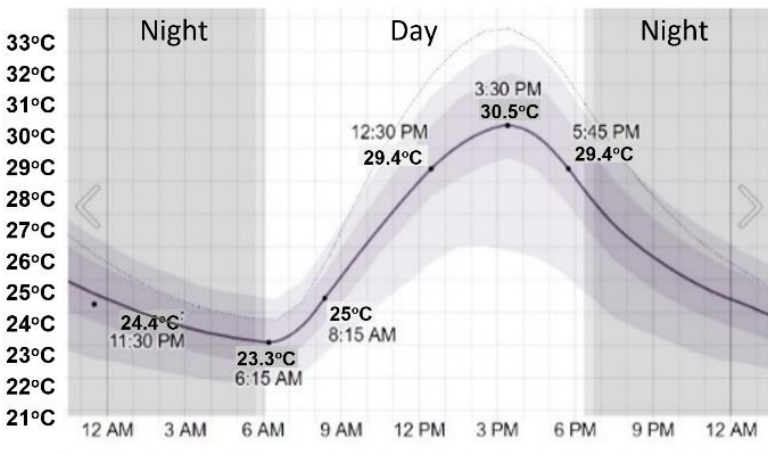

b)

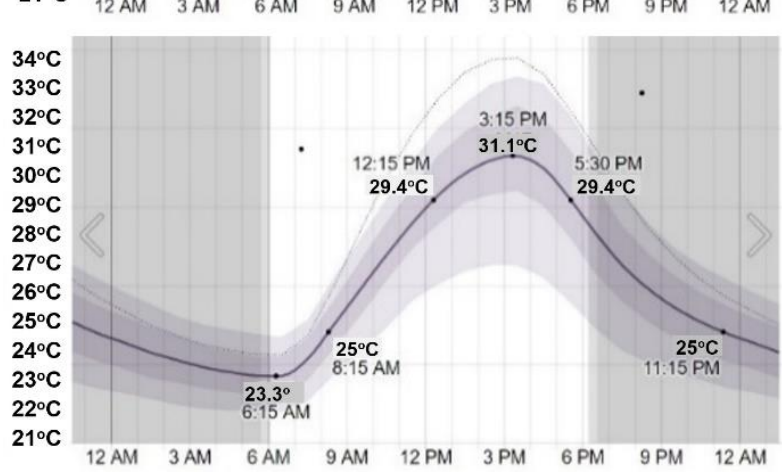

Figure 8. Average daily environmental temperature in Kinshasa during a) January 2020, b) February 2020 and c) March 2020. power increases, but the increase is less than in the ideal curve due to the conversion efficiency reduction, since the thermal excitation of electrons dominates the properties of the active material. However, the two typologies of solar panels (mono-Si and poly-Si) exhibit slightly different behaviours. Up to $35^{\circ} \mathrm{C}$, both panels show the same trend, but at higher temperatures, the delivered power increases much less for the poly-Si panel. This is due to the fact that the active material in the poly-Si panel contains multiple crystals that prevent charge carriers from travelling a long distance before recombining (i.e. short diffusion length), leading to losses due to high temperatures, which mainly concerns the back of the panel. This loss increases the temperature within the robot's electronic components, thus inducing thermal drifts. To avoid this problem, a gap was created between the panel and the part immediately below it, where the electronic section is located, to allow natural cooling from the airflow induced by the robot's movement [36]. This aspect is crucial, since the impact of temperature is a constraint for the use of remotely-controlled autonomous wheeled robots in long-term outdoor operations. Three main factors influence the efficiency of PV panels: solar irradiance, technology and temperature. The exposure angle to the solar light and humidity are also important.

The temperature of the electronic section was monitored using a PT100 sensor located near this section, which was used to stop the mobile robot if a temperature higher than $65-70{ }^{\circ} \mathrm{C}$ was detected [37].

The robot was constructed with the aim of detecting parameters in harsh environments where human intervention could be dangerous. In this context, several applicative scenarios can be identified, such as the inspection of empty tanks that previously contained chemicals, fuels or cereals or environments in which fires or gas leaks have occurred. The mobile robot is equipped with several sensors able to verify the absence of dangers to human health in the considered environment, thus allowing the subsequent intervention of a human operator [38].

The mobile robot includes a multi-directional flame sensor constituted by five-directional IR photo-transistors ( $\Delta \lambda$ equal to $760 \div 1100 \mathrm{~nm}$ ) that ensure a wide detection range (greater than 120 degrees); each transistor is arranged in common emitter configuration, with the output provided directly (analogue output) or digitalised using an LM393 comparator (manufactured by Texas Instruments) that compares the analogue voltage with

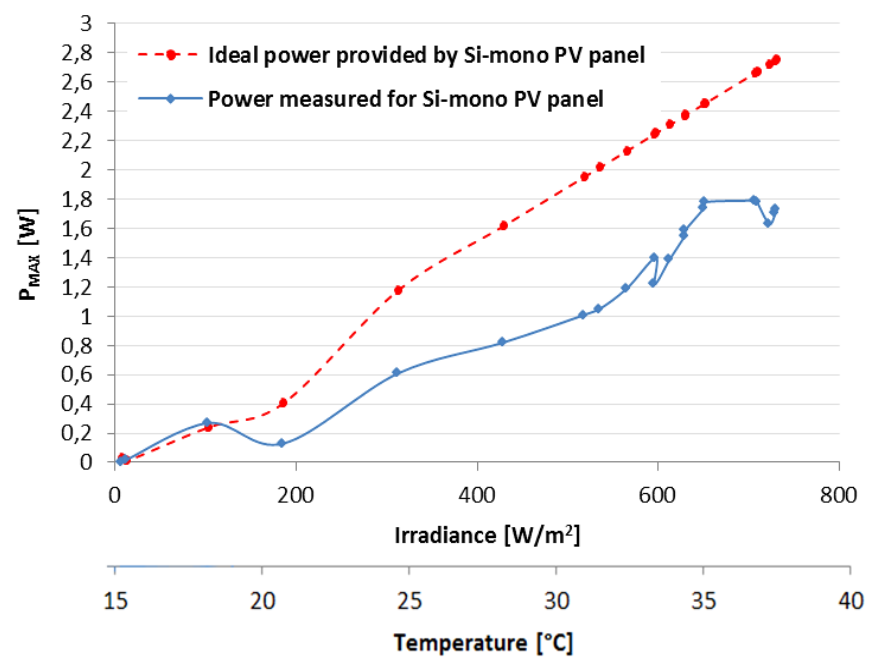

Figure 9. Trend of the maximum power provided by the $1.8 \mathrm{~W}$ mono-Si PV panel (model PETC-SE1.8) as a function of solar irradiance and a linear model of the increase of the panel's temperature induced by the incident radiation. 


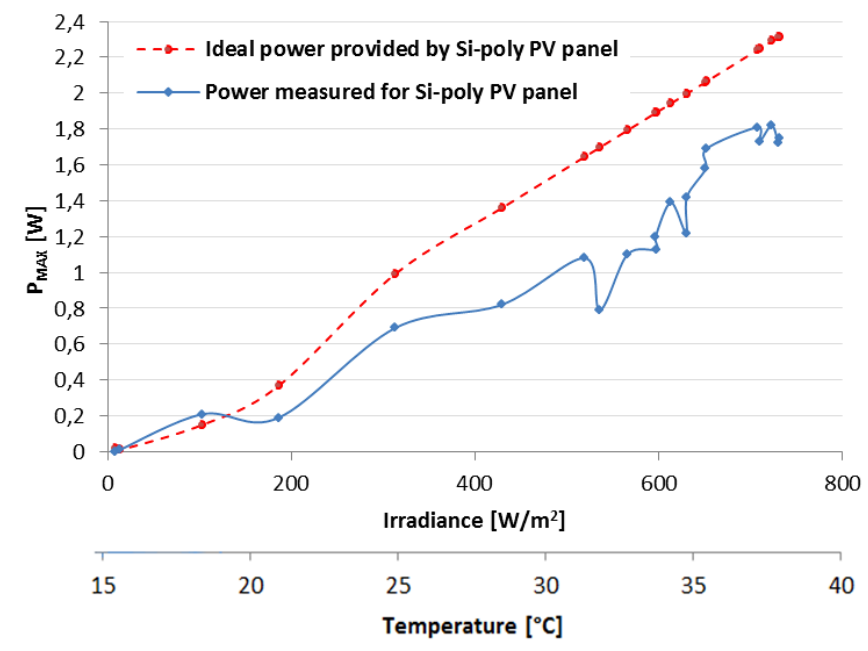

Figure 10. Trend of the maximum power provided by the $2 \mathrm{~W}$ poly-Si solar panel (model $130110-3$ ) as a function of solar irradiance and a linear mode of the increase of the panel's temperature induced by the incident radiation.

a set voltage threshold. The five digital outputs are connected to five general-purpose input/output pins on the Arduino board to detect fire and discern its location (Figure 11a).

Furthermore, the robot is equipped with two gas sensors, namely a ZE07-CO module (manufactured by Winsen Inc.) and a CCS 811 breakout board (manufactured by AMS). The ZE07$\mathrm{CO}$ is constituted by a ME2-CO sensor with a conditioning/acquisition board based on a potentiostatic circuit (Figure 11b). The ME2-CO sensor is a two-terminal electrochemical sensor, featuring high precision, low consumption, a wide linearity range and low cross-sensitivity with respect to other gaseous species; it has a wide detection range (from 0 to $1,000 \mathrm{ppm}$ ) and high sensitivity $(0.015 \pm 0.005$ $\mu \mathrm{A} / \mathrm{ppm})$. The on-board acquisition section of the ZE07-CO module is based on an STM32F040F4 microcontroller (manufactured by STMicroelectronics), which acquires and elaborates the analogue signal provided by the conditioning section, making it available in the correct form to the master microcontroller via the UART interface. The CCS811 digital gas sensor is an ultra-low-power metal oxide (MOX) gas sensor that detects the equivalent $\mathrm{CO}_{2}\left(\mathrm{eCO}_{2}\right)$ and the concentration of total volatile organic compounds (TVOCs) (Figure 11c) [39].

Through intelligent algorithms applied to current and voltage values provided by the MOX sensor, the gas concentration values are made available to a master microcontroller unit (MCU) employing the $\mathrm{I}^{2} \mathrm{C}$ interface. In addition, the sensor has three low-power modes optimised to extend the autonomy of portable applications. The CCS811 features a wide detection range $(0 \div$ $1187 \mathrm{ppb}$ for TVOC and $400 \div 8192 \mathrm{ppm}$ for $\mathrm{CO}_{2}$ ), high sensitivity, low power consumption and high robustness to external agents (i.e. high humidity and temperature as well as the presence of dust), making it suitable for the considered application.

A Neo-6M GPS receiver (manufactured by u-blox) has been installed on the mobile robotic vehicle to provide the user with information about the vehicle's position (Figure 11d); it is very compact $(16 \mathrm{~mm} \times 12.2 \mathrm{~mm} \times 2.4 \mathrm{~mm})$ and features different power and memory modalities, which makes it ideal for applications in which there are space constraints or the power is supplied by batteries. The module interfaces with the Arduino Uno board using UART serial communication and provides GPS coordinates via National Marine Electronics Association a)

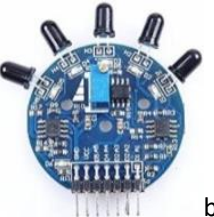

b)
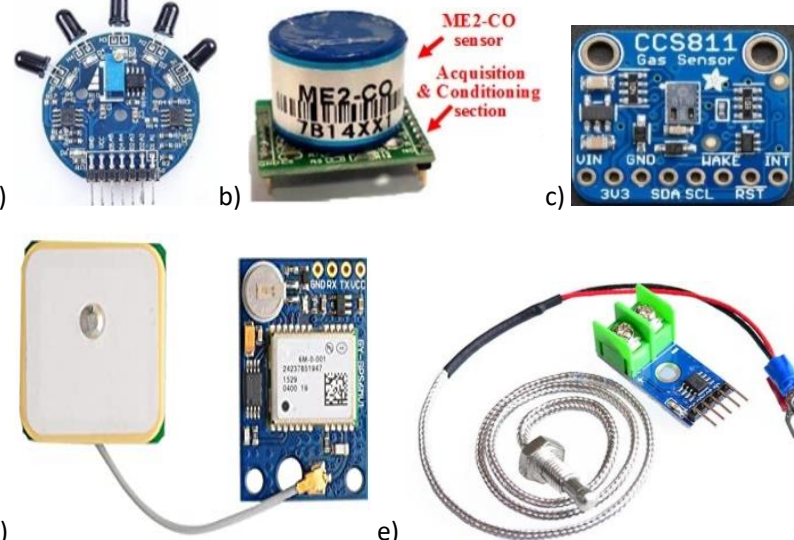

e)

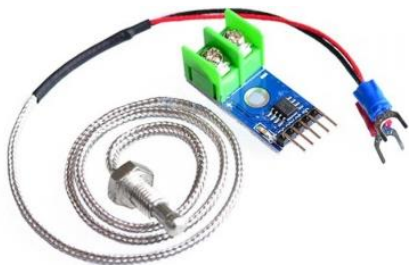

Figure 11. Set of sensors and devices equipping the designed mobile robot: a) multi-directional fire sensor, b) Winsen ZE07-CO gas sensor module, c) CCS811 gas sensing board, d) NEO-6M GPS module and e) MAX6675 module with K-type thermocouple.

messages. Finally, the sensing system includes a K-type thermocouple (temperature detection range $0 \div 1024{ }^{\circ} \mathrm{C}$ ) interfaced with a conditioning and acquisition board based on the MAX6675 IC (manufactured by Maxim Integrated), making the temperature data available to the host MCU by SPI (Figure 11e). The thermocouple was placed on the external housing of the robot to detect environmental temperature [40].

In Figure 12, a schematic representation of the developed sensing and communication section installed on the mobile sensor-based robot is shown.

The sensing system is enabled by an external command sent by the smartphone application via Bluetooth communication; then, the sensing system takes 10 minutes to warm up the CCS811 gas sensor, allowing it to reach the optimal operating temperature. Afterwards, using the HC-06 Bluetooth module, the mobile robot transmits a packet containing appropriately arranged data every 60 seconds to the developed IoTool smartphone application, which displays the incoming data and shares them with the IBM Watson Cloud, where they can be remotely visualised and analysed. Through the Io'Tool application, the smartphone acts as an IoT gateway, providing internet access to the developed application and enabling the use of the mobile robot in areas where no access points are available (outdoors and/or in remote zones). The acquired data are shared

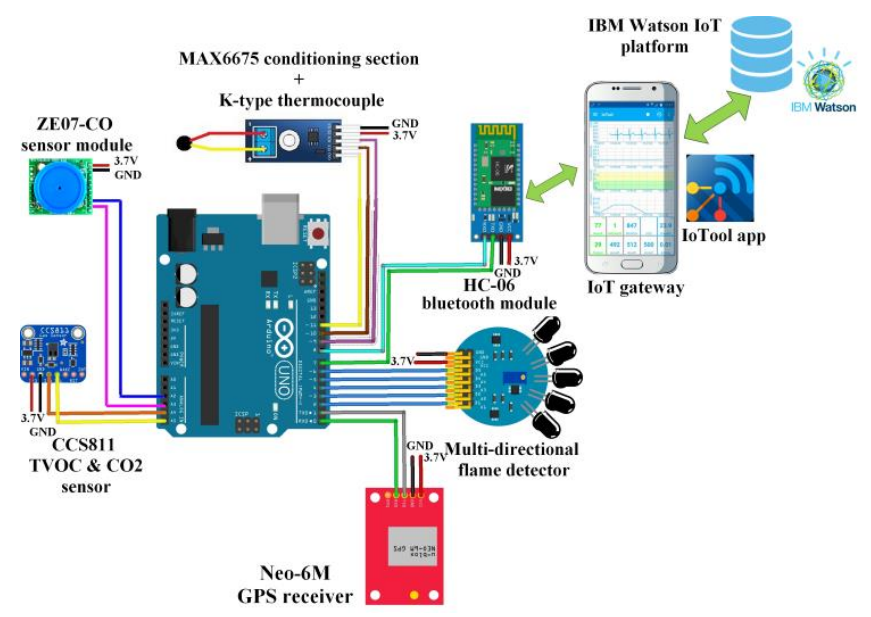

Figure 12. Graphical representation of the designed sensing system equipping the mobile vehicle; the acquired data and alarm conditions are synchronised with a smartphone acting as an loT gateway. 
with a cloud platform, using the message queue telemetry transport protocol in JavaScript Object Notation (JSON) to create packets, which allows remote monitoring, storing and processing. Thus, a remote operator can access the acquired data in real time, enabling better coordination of rescue, monitoring or maintenance activities. As described above, the developed mobile robot can support remediation operations in cramped places, such as tanks, pipelines and drains, or harsh environments, such as a room where there has been a fire or a dangerous gas leak. A remote supervisor's availability enables, for instance, more rapid deployment of rescue teams or additional equipment in the presence of an abnormal CO concentration or the resumption of a fire inside an environment. In addition, the IoTool application allows the robot to receive remote commands via JSON packets; for instance, the robot could be signalled to optimise its power consumption or reduce the motors' speed. Furthermore, the application allows users to configure trigger and action events to send alarm messages via short message service and/or email if an abnormal value is detected for a monitored parameter [40], [41].

Finally, in Figure 13, two screenshots of the developed IoTool application are shown, caught during a test of the robot's sensing system; the temporal trends of the interest parameters $\left(\mathrm{CO}, \mathrm{CO}_{2}\right.$, TVOC and temperature) are plotted for the user.

The absorbed current values measured on the different electronic units included in the acquisition, driving and communication systems are summarised in Table 1 . These were determined for each unit's power supply line using the same experimental setup and methodology previously employed to measure the total robot's power consumption.

The overall current consumption of the mobile robot's acquisition and communication system was about $70.4 \mathrm{~mA}$ during data acquisition and reached peak values of $78.9 \mathrm{~mA}$ during the communication phase, which, however, corresponds to less than $1 \%$ of the robot's operating time. Furthermore, the driving system, constituted by an L298N motor driver, statically consumed $32.0 \mathrm{~mA}$, representing the main contribution to the absorbed current. The sensing system can be disabled through another command sent by Bluetooth communication, which acts on a Mosfet switch placed in series to the supply line of the CO sensor module, temperature sensor and flame detector and sets

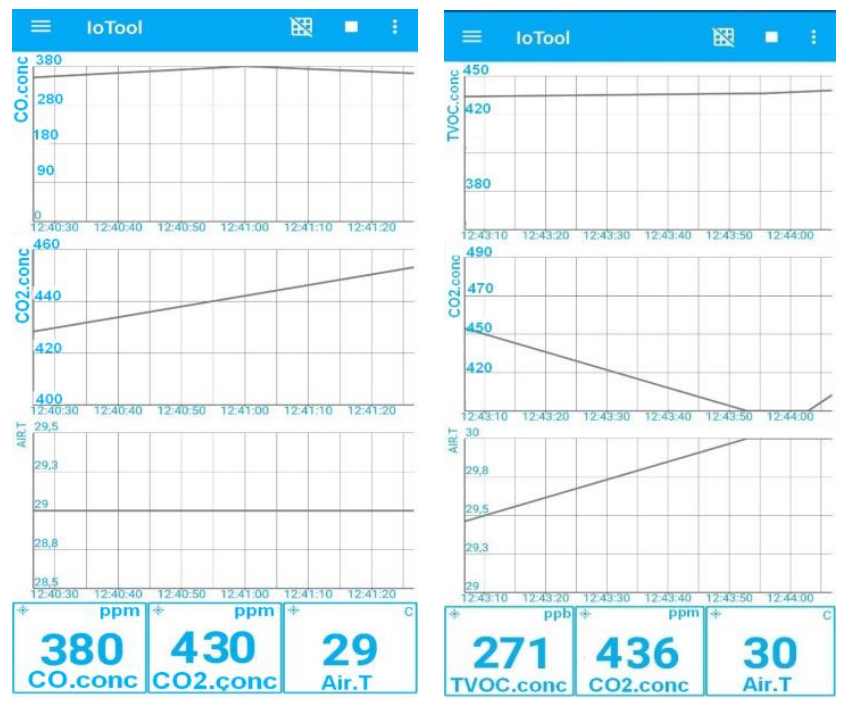

Figure 13. Screenshot of the loTool application during experiments performed on the mobile robot's sensing system, showing the temporal trends of the interest parameters.
Table 1. Summary of the power consumption of the different units included in the acquisition, driving and communication systems of the mobile robot.

\begin{tabular}{cc}
\hline Component & Current Consumption \\
\hline Arduino Uno board & $24.2 \mathrm{~mA}$ \\
HC-06 Bluetooth module & $8.5 \mathrm{~mA}$ (communication mode) \\
& $0.5 \mathrm{~mA}$ (sleep mode) \\
CCS811 TVOC/eCO 2 gas sensor & $30.4 \mathrm{~mA}$ (active mode) \\
Neo-6M GPS receiver & $18 \mu \mathrm{\mu A}$ (sleep mode) \\
Multi-directional flame sensor & $8.2 \mathrm{~mA}$ (average value) \\
ZE07-CO module & $2.2 \mathrm{~mA}$ \\
K-type thermocouple + & $4.7 \mathrm{~mA}$ \\
MAX6675 module & $0.7 \mathrm{~mA}$ \\
L298N motor driver & $32.0 \mathrm{~mA}$ (quiescent current) \\
\hline
\end{tabular}

the GPS receiver and the CCS811 gas sensor to low-power modality, obtaining a drastic reduction of the absorbed current (as low as dozens of $\mu \mathrm{A}$ ).

\section{CONCLUSIONS}

The paper has presented the outcomes of a conceptual approach using RE to design autonomous wheeled robots for monitoring harsh environments. Energy consumption was a major focus, and the robot was equipped with a combination of embedded batteries and a solar energy harvesting section, including two different typologies of PV panels. The paper outlines the design of a wheeled sensor-based robot by taking into account the energy consumption of various components and the energy loss induced by the vehicle's operation. Using a $\mathrm{RE}$ process and SolidWorks software, the whole robot was redesigned. After the integration of the solar harvesting system, which provided approximately $20 \%$ of the total power required by the vehicle, experimental tests were carried out, taking into account friction and the loss of mechanical energy due to other displacement difficulties. Tests were performed in two specific conditions: normal operating mode (Figure 7a) and stress conditions simulating wheel blockages or rough paths, which both involve greater current demands (Figure 7b).

The PV panel plays a key role in these latter conditions, assuming that solar energy is available; two different PV panels (mono-Si and poly-Si) were alternatively mounted on the roof of the robotic vehicle for the outdoor tests. Mono-Si solar panels are usually of premium quality, with higher efficiencies and sleeker aesthetics. Since the material used to produce solar cells is single-crystal silicon, the electrons have more room to move; thus, mono-Si panels are more efficient than poly-Si panels. The latter are made by melting many fragments of silicon to create the wafers for the PV panel. These panels are also referred to as 'many-crystal' or 'multi-crystalline' silicon. Since there are many crystals in each cell, the electrons have less freedom to move; this results in lower efficiency than that typical of the mono-Si panels [42].

An electronic conditioning component was developed for the PV harvesting system that recharges a 4,000 $\mathrm{mAh}$ auxiliary LiIon battery and dynamically manages its activation based on the robot's current absorption. The power trends for the two typologies of PV panels as a function of solar irradiance and panel temperature are shown in Figure 9 and Figure 10. As foreseen, the maximum power was close to $2 \mathrm{~W}$; however, beyond $35^{\circ} \mathrm{C}$, a decrease of the harvested electrical power was observed, especially for the poly-Si panel. 
Finally, a sensing system was designed and installed in the vehicle to allow the monitoring of harsh environments in which human intervention would be too dangerous. It includes a wide set of sensors (for flames, toxic gas species and temperature) and devices (a GPS receiver and a Bluetooth module) to detect the environmental parameters and track the vehicle's position. Furthermore, an HC-06 Bluetooth module was used to transmit the acquired data to the developed IoTool mobile application, where they can be displayed and analysed by the user.

\section{ACKNOWLEDGEMENT}

The authors gratefully thank the members of the mechatronics laboratory at ISTA University (Kinshasa, DR Congo) and Moise Avoci Ugwiri of the University of Salerno (Fisciano, Italy) for their technical support during the experiments. The research is part of a cooperation between ISTA University and the University of Salento supervised by Prof. A. Lay-Ekuakille.

\section{REFERENCES}

[1] T. Addabbo, A. Fort, M. Mugnaini, L. Parri, S. Parrino, A. Pozzebon, V. Vignoli, A low-power IoT architecture for the monitoring of chemical emissions, Acta IMEKO 8(2) (2019), pp. 53-61.

DOI: $10.21014 /$ acta imeko.v8i2.642

[2] A. Bernieri, D. Capriglione, L. Ferrigno, M. Laracca, Design of an efficient mobile measurement system for urban pollution monitoring, Acta IMEKO 1(1) (2012), pp. 77-84.

DOI: $10.21014 /$ acta imeko.v1i1.27

[3] A. Lay-Ekuakille, S. Ikezawa, M. Mugnaini, R. Morello, Detection of specific macro and micropollutants in air monitoring, review of methods and techniques, Measurement 98(1) (2017), pp. 49-59. DOI: 10.1016/i.measurement.2016.10.055

[4] A. P. Plonski, J. Vander Hook, V. Isler, Environment and solar map construction for solar-powered mobile systems, IEEE Transactions on Robotics 32(1) (2016), pp. 70-82. DOI: $10.1109 /$ TRO.2015.2501924

[5] WHO, Diseases, Coronavirus disease (COVID-19). Online [Accessed 21 June 2021] https://www.who.int/emergencies/diseases/novel-coronavirus2019.

[6] A. Lay-Ekuakille, G. Griffo, P. Visconti, P. Primiceri, R. Velazquez, Leaks detection in waterworks: comparison between STFT and FFT with an overcoming of limitations, Metrology and Measurement Systems 24(4) (2017), pp. 631-644.

DOI: $10.1515 / \mathrm{mms}-2017-0049$

[7] J. Nádvorník, P. Smutný, Remote control robot using android mobile device, Proc. of the $15^{\text {th }}$ International Carpathian Control Conference (ICCC), Velke Karlovice, Czech Republic, 28-30 May 2014, pp. 373-378.

DOI: $10.1109 /$ CarpathianCC.2014.6843630

[8] P. Visconti, C. Orlando, P. Primiceri, Solar powered WSN for monitoring environment and soil parameters by specific app for mobile devices usable for early flood prediction or water savings, Proc. of $16^{\text {th }}$ IEEE Int. Conf. on Environment and Electrical Engineering, Florence, Italy, 7 - 10 June 2016, 6 pp. DOI: $10.1109 /$ EEEIC.2016.7555638

[9] P. Visconti, P. Primiceri, C. Orlando, Solar powered wireless monitoring system of environmental conditions for early flood prediction or optimized irrigation in agriculture, ARPN Journal of Engineering and Applied Sciences 11(7) (2016), pp. 4623-4632.

[10] P. Visconti, R. de Fazio, P. Primiceri, D. Cafagna, S. Strazzella, N. I. Giannoccaro, A solar-powered fertigation system based on lowcost wireless sensor network remotely controlled by farmer for irrigation cycles and crops growth optimization, International Journal of Electronics and Telecommunications 66(1) (2020), pp.
59-68.

DOI: $\underline{10.24425 / \text { ijet.2019.130266 }}$

[11] P. Visconti, R. de Fazio, R. Velázquez, C. Del-Valle-Soto, N. I. Giannoccaro, Development of sensors-based agri-food traceability system remotely managed by a software platform for optimized farm management, Sensors 20(13) (2020) art. 3632. DOI: $10.3390 / \mathrm{s} 20133632$

[12] V. Popovski, N. Ackovska, A robotic system powered by solar energy, Proc. of the $10^{\text {th }}$ Conference for Informatics and Information Technology (CIIT 2013), Bitola, Macedonia, 15 May 2013, pp. 85-88.

[13] B. P. Gautam, K. Wasaki, N. Sharma, Using a solar powered vehicle to monitor and manage unstable networks, International Journal of Future Computer and Communication 3(6) (2014), pp. 415-420. DOI: $10.7763 /$ IJFCC.2014.V3.339

[14] M. M. Warekar, B. T. Salokhe, Solar powered robotic vehicle, International Journal of Advanced Research in Computer and Communication Engineering 4(5) (2015), pp. 1-4.

[15] S. Rajeswari, O. K. Jayaprasanth, P. Vetrivel, K. Gnanaprakasam, Ideal battery charging for a solar-powered robotic vehicle using microcontroller, International Journal of Computer Science and Mobile Computing 4(3) (2015), pp. 557-567.

[16] T. Dewi, P. Risma, Y. Oktarina, M. Taufik Roseno, H. M. Yudha, A. S. Handayani, Y. Wijanarko, Survey on solar cell; the role of solar cell in robotics and robotics application in solar cell industry, Proc. Forum in Research, Science and Technology (FIRST), Palembang, Indonesia, 18-19 October 2016, pp. 19-22.

[17] T. Dewi, P. Risma, Y. Oktarina, A. Taqua, Rusdianari, H. Renaldi, Experimental analysis on solar powered mobile robot as the prototype for environmentally friendly automated transportation, Journal of Physics: Conference Series, iCAST-ES2019 1450 (2020), pp. 1-7.

DOI: $10.1088 / 1742-6596 / 1450 / 1 / 012034$

[18] D. S. Wikacsono, A. Musafa, Design and implementation of dual axis solar tracker PV to increase cleaning robot operating time, Journal of Physics: Conference Series 1376 (2019), pp. 1-7. DOI: $\underline{10.1088 / 1742-6596 / 1376 / 1 / 012022}$

[19] O Bartlett, C. Gurau, L. Marchegiani, I. Posner, Enabling intelligent energy management for robots using publicly available maps, Proc. of the IEEE/RSJ International Conference on Intelligent Robots and Systems (IROS), Daejeon, Korea, 9 - 14 October 2016, pp. 2224-2229.

DOI: $10.1109 /$ IROS.2016.7759348

[20] L. Hou, L. Zhang, J. Kim, Energy modelling and power measurement for mobile robot, Energies 12(27) (2019), pp. 1-15. DOI: $10.3390 /$ en12010027

[21] I. Doroftei, V. Grosu, V. Spinu, Design and control of an omnidirectional mobile robot, in: Novel Algorithms and Techniques in Telecommunications, Automation and Industrial Electronics. T. Sobh, K. Elleithy, A. Mahmood, M. A. Karim (editors). Springer, Dordrecht, 2008, ISBN 978-1402087363, pp. 105-110. DOI: $10.1007 / 978-1-4020-8737-019$

[22] M. M. Islam, R. K. Saha, A. A. Abdlullah, M. Z. Haq, Fabrication of autonomous wheeled mobile robot for industrial applications using appropriate technology, International Journal of Mechanical and Materials Engineering 4(10) (2010), pp. 1126-1130. DOI: $10.5281 /$ zenodo. 1332720

[23] SolidWorks. Online [Accessed 29 July 2020] www.solidworks.com

[24] Microchip. Online [Accessed 29 July 2020] www.microchip.com/wwwproducts/en/ATmega328L

[25] R. de Fazio, D. Cafagna, G. Marcuccio, P. Visconti, Limitations and characterization of energy storage devices for harvesting applications, Energies 13(4) (2020) art. 783. DOI: $10.3390 /$ en13040783

[26] P. Visconti, A. Lay-Ekuakille, P. Primiceri, G. Cavalera, Wireless energy monitoring system of photovoltaic plants with smart antitheft solution integrated with control unit of household electrical consumption, Int. Journal on Smart Sensing and Intelligent 
Systems 9(2) (2016), pp. 681-708.

DOI: $10.21307 /$ ijssis-2017-890

[27] G. Bucci, D. Bentivoglio, M. Belletti, A. Finco, Measuring a farm's profitability after adopting precision agriculture technologies: a case study from Italy, Acta IMEKO 9(3) (2020), pp. 65-74. DOI: 10.21014 /acta imeko.v9i3.799

[28] P. Visconti, P. Primiceri, R. Ferri, M. Pucciarelli, E. Venere, An overview on state-of-art energy harvesting techniques and related choice criteria: a WSN node for goods transport and storage powered by a smart solar-based EH system, Int. Journal of Renewable Energy Research 7(1) (2017), pp. 1281-1295.

[29] P. Kapita Mvemba, S. Kidiamboko Guwa Gua Band, A. LayEkuakille, N. I. Giannoccaro, Advanced acoustic sensing system on a mobile robot: design, construction and measurements, IEEE Instrumentation and Measurement Mag. 21(2) (2018), pp. 4-9. DOI: $10.1109 /$ MIM.2018.8327971

[30] N. I. Giannoccaro, L. Spedicato, New methods for robotic perception by using in-air sonar data, International Journal of Advanced Robotic Systems 13(1) (2016), pp. 1-14. DOI: $10.5772 \% 2 \mathrm{~F} 62098$

[31] N. I. Giannoccaro, L. Spedicato, Exploratory data analysis for robot perception of room environments by means of an in-air sonar scanner, Ultrasonics 53(6) (2013), pp. 1163-1173.

DOI: $10.1016 /$ j.ultras.2013.01.015

[32] M. Mathew, M. N. Kumar, R. P. Koroth, Outdoor measurement of mono and poly c-Si PV modules and array characteristics under varying load in hot-humid tropical climate, Materials Today: Proceedings 5(2) (2018), pp. 3456-3464. DOI: $10.1016 /$ i.matpr.2017.11.592

[33] WeatherSpark. Online [Accessed 29 July 2020] https://weatherspark.com/d/78302/3/10/Average-Weatheron-March-10-in-Kinshasa-Congo---Kinshasa

[34] P. K. Basu, S. Kumbhar; K. P. Sreejith; T. S. Yadav, A. Kottantharayil, B. M. Arora, K. L. Narasimhan, A. K. Sharma, Active area cell efficiency $(19 \%)$ monocrystalline silicon solar cell fabrication using low-cost processing with small footprint laboratory tools, Bull. Mater. Sci. 42(33) (2019), pp. 1-11. DOI: $10.1007 / \mathrm{s} 12034-018-1711-2$

[35] P. Jumrusprasert, G. Smith, L. Kirkup, Comparing the efficiency of fixed solar cell panels in a tropical location, in: Proc. of the ISES
World Congress 2007 (Vol. I - Vol. V). D. Y. Goswami, Y. Zhao (editors). Springer, Berlin, Heidelberg, 2009, ISBN 978-3-54075996-6, pp. 1478-1483.

DOI: $10.1007 / 978-3-540-75997-3 \quad 300$

[36] P. Visconti, P. Costantini, C. Orlando, A. Lay-Ekuakille, G. Cavalera, Software solution implemented on hardware system to manage and drive multiple bi-axial solar trackers by PC in photovoltaic solar plants, Measurement 76 (2015), pp. 80-92. DOI: $10.1016 /$ i.measurement.2015.08.024

[37] Components101. Online: [Accessed 29 July 2020] https://components101.com/sensors/pt100-rtd-temperature$\underline{\text { sensor }}$

[38] R. de Fazio, D. Cafagna, G. Marcuccio, A. Minerba, P. Visconti, A multi-source harvesting system applied to sensor-based smart garments for monitoring workers' bio-physical parameters in harsh environments, Energies 13(9) (2020) art. 2161. DOI: $10.3390 /$ en13092161

[39] P. Visconti, R. de Fazio, P. Costantini, S. Miccoli, D. Cafagna, An innovative complete solution for health safety of children unintentionally forgotten in a car: a smart Arduino-based system with user app for remote control, IET Science, Measurement \& Technology 14(6) (2020), pp. 665-675. DOI: 10.1049 /iet-smt.2018.5664

[40] P. Visconti, A. Lay-Ekuakille, P. Primiceri, G. Ciccarese, R. De Fazio, Hardware design and software development for a white LED-based experimental spectrophotometer managed by a PICbased control system, IEEE Sensors Journal 17(8) (2017), pp. 2507-2515.

DOI: 10.1109 /JSEN.2017.2669529

[41] E. Balestrieri, L. De Vito, F. Lamonaca, F. Picariello, S. Rapuano, I. Tudosa, Research challenges in measurements for Internet of Things systems, Acta IMEKO 7(4) (2018), pp. 82-94. DOI: $10.21014 /$ acta imeko.v 714.675

[42] A. Carullo, A. Castellana, A. Vallan, A. Ciocia, F. Spertino, In-field monitoring of eight photovoltaic plants: degradation rate over seven years of continuous operation, Acta IMEKO 7(4) (2018), pp. 75-81. DOI: $10.21014 /$ acta imeko.v7i4.599 